\title{
Effectiveness of a girls' empowerment programme on early childbearing, marriage and school dropout among adolescent girls in rural Zambia: study protocol for a cluster randomized trial
}

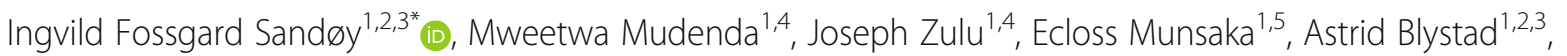
Mpundu C. Makasa 1,4, Ottar Mæstad ${ }^{1,6}$, Bertil Tungodden 1,6,7 ${ }^{1,}$ Choolwe Jacobs ${ }^{1,4}$, Linda Kampata 1,2,4, Knut Fylkesnes ${ }^{1,2}$, Joar Svanemyr ${ }^{1,2,6}$, Karen Marie Moland ${ }^{1,2}$, Richard Banda ${ }^{2,8}$ and Patrick Musonda 1,2,4

\begin{abstract}
Background: Adolescent pregnancies pose a risk to the young mothers and their babies. In Zambia, 35\% of young girls in rural areas have given birth by the age of 18 years. Pregnancy rates are particularly high among out-of-school girls. Poverty, low enrolment in secondary school, myths and community norms all contribute to early childbearing. This protocol describes a trial aiming to measure the effect on early childbearing rates in a rural Zambian context of (1) economic support to girls and their families, and (2) combining economic support with a community intervention to enhance knowledge about sexual and reproductive health and supportive community norms.

Methods/design: This cluster randomized controlled trial (CRCT) will have three arms. The clusters are rural schools with surrounding communities. Approximately 4900 girls in grade 7 in 2016 will be recruited from 157 schools in 12 districts. In one intervention arm, participating girls and their guardians will be offered cash transfers and payment of school fees. In the second intervention arm, there will be both economic support and a community intervention. The interventions will be implemented for approximately 2 years. The final survey will be 4.5 years after recruitment. The primary outcomes will be "incidence of births within 8 months of the end of the intervention period", "incidence of births before girls' 18th birthday" and "proportion of girls who sit for the grade 9 exam". Final survey interviewers will be unaware of the intervention status of respondents. Analysis will be by intention-to-treat and adjusted for cluster design and confounders. Qualitative process evaluation will be conducted.
\end{abstract}

Discussion: This is the first CRCT to measure the effect of combining economic support with a community intervention to prevent adolescent childbearing in a low- or middle-income country. We have designed a programme that will be sustainable and feasible to scale up. The findings will be relevant for programmes for adolescent reproductive health in Zambia and similar contexts.

Trial registration: ISRCTN registry: ISRCTN12727868, (4 March 2016).

Keywords: Adolescent pregnancy, Early marriage, School enrolment, Economic support, Community dialogue, Cash transfer, Sexual and reproductive health, School dropout, Poverty

\footnotetext{
* Correspondence: ingvild.sandoy@uib.no

${ }^{1}$ Center for Intervention Science in Maternal and Child Health (CISMAC),

Centre for International Health $(\mathrm{ClH})$, University of Bergen, Bergen, Norway

${ }^{2}$ Centre for International Health, University of Bergen, Bergen, Norway

Full list of author information is available at the end of the article
} 


\section{Background}

Approximately 7.3 million girls below age 18 give birth in low- and middle-income countries (LMICs) every year [1]. Maternal complications are estimated to be the fourth most common cause of death in girls aged 15-19 in LMICs [2], and the risks of prematurity and low birth weight are high in adolescent pregnancies [3-5], with consequent higher morbidity and mortality [4, 6-10]. The younger the mother is, the higher is the risk of complications both for her and the child [3], and childbearing before age 16 is of particular concern [4, 6-8].

Early pregnancy is often associated with early marriage and school dropout, and poverty contributes to all three. Observational studies from low-income countries indicate that young women who quit school early are more likely to marry and become pregnant earlier than those who stay in school [11-15]. Increased schooling has also been associated with better health of women and their children $[16,17]$. In the last decades primary school enrolment has increased significantly in many poor countries. However, enrolment at secondary level is much lower than at primary level in most LMICs, particularly for girls [18]. This may be due to limited availability of and longer distances to school, higher fees, or to early marriage or pregnancy. Moreover, there may be a preference to support boys' education rather than girls' [19]. In many societies marrying off a girl may be regarded as better to secure her future than schooling, and the bride-price paid to the girl's family may be an important source of income. Once a girl is married, she is expected to start childbearing. Moreover, where access to cash is severely limited, many unmarried adolescent girls engage in sexual relationships, even if not socially acceptable, to receive gifts and cash [20-22].

We did a systematic search ${ }^{1}$ in 16 databases $^{2}$ for randomized controlled trials (RCTs) in LMICs that assessed interventions targeting adolescent childbearing and marriage. Recent systematic reviews on adolescent pregnancy $[23,24]$ and childbearing [25] and early marriage [26, 27] were also examined for relevant original articles. We focused on trials that included girls younger than 18 . Three trials examined the effects of support to girls to reduce the cost of schooling. In Kenya, girls provided with free school uniforms were less likely to drop out before completing primary school, and proxy reports by classmates indicated reduced risks of early marriage and childbearing [28]. A trial in Zimbabwe found that a programme targeting orphan girls, offering payment of school fees and free uniform, led to an $80 \%$ reduction in school dropout, and $60 \%$ reduction in marriage rates in the next 2 years [29]. A trial in Malawi found that payment of school fees combined with small cash transfers to adolescent girls and their families resulted in lower prevalence of human immunodeficiency virus
(HIV) and Herpes simplex virus type 2 (HSV-2) in the next 18 months among girls enrolled in school at baseline [30]. The trial also found that unconditional cash transfers led to reduced marriage and pregnancy rates whereas no significant change was seen in these outcomes in the group provided with cash transfers conditional on school attendance [31]. Quasi-experimental evaluations of unconditional and conditional cash transfer programmes in Kenya [32], Pakistan, [33] and Mexico [34] have also found effects on adolescent childbearing and/or marriage. More recently, two RCTs on the effects of conditional cash transfer programmes on HIV have been conducted in South Africa [35]. They found no effect on HIV incidence [22]. Thus effects of cash transfers appear to be context dependent [24], and there is a need for further evaluations of such programmes in new settings, alone and in combination with other interventions [22].

Comprehensive sexual and reproductive health education (CSRHE) programmes can equip adolescents with knowledge and skills to prevent unwanted pregnancy even if they are sexually active. Reviews of evaluations of sexual and reproductive health education programmes worldwide indicate that effective curricula are intensive [36], include student active teaching [37], and incorporate discussions around gender and power dynamics [38]. Our systematic literature review of RCTs identified five cluster randomized controlled trials (CRCTs) from LMICs that studied the impact of sexual and reproductive health (SRH) education programmes on early childbearing and marriage. The findings were mixed: a CRCT in Kenya found that pupils exposed to a curriculum informing them of the higher risk of HIV infection associated with having older sexual partners, had 28\% lower pregnancy rates 12 months later [39], whereas training of teachers in the national HIV/AIDS curriculum promoting sexual abstinence until marriage, indicated no effect on adolescent childbearing after 2, 3,5 and 7 years $[28,39,40]$. This is in line with a systematic review of randomized studies assessing abstinenceonly programmes in the US, finding no protective effects on self-reported sexual behaviour, sexually transmitted infection (STI) diagnosis, or pregnancies [41]. In Uganda, a CRCT assessing a combination of a life skills programme (which included comprehensive sexual and reproductive health education) and vocational skills training, found lower probability of adolescent girls in the intervention arm having children after 2 years compared to the control [42]. In South Africa, a CRCT evaluated the impact of a 50-hour interactive HIV prevention programme focusing on SRH and gender relations was evaluated. The intervention was delivered over 8 weeks to girls and boys (in- and out-of-school) aged 16-19. After 2 years the proportion of girls who were pregnant tended to be higher in the intervention arm (OR 1.45; 0.92-2.28), there was no difference 
in HIV incidence between the two arms, whereas the HSV-2 incidence was 33\% lower in the intervention than control group [43]. Another CRCT in South Africa studied a comprehensive teenage pregnancy prevention programme with 12 weekly sessions among pupils in grade 8 and found no impact on pregnancy rates after 8 months [44]. In Tanzania, a CRCT examined the effects of an intervention with the following four components: (1) a teacher-led, SRH school programme in grades 5-7; (2) training and supervision of health workers in youthfriendly health services; (3) community-based condom promotion and distribution by adolescents; and (4) 1week mobilization in each community and annual youth health weeks. An evaluation 3 years after the start of the intervention found effects on SRH knowledge and selfreported condom use among the youths, but no impact on the incidence of HIV, HSV-2 or pregnancy despite high coverage and high quality of the implementation [45]. Qualitative evaluation during the first years of the intervention indicated that adolescents found it difficult to use the new knowledge and skills because of attitudes and practices in the community. The authors suggest this may imply that SRH education may not be effective on its own, but needs to be combined with efforts to "address broader sexual norms" and future aspirations [46-48].

The need to find ways to prevent early marriage and pregnancy is high on the political agenda in Zambia. As many as $35 \%$ of young rural 18-year-old girls have given birth, and the median age at marriage was 18 years in 2013/2014 [49]. According to the 2010 Zambia Census of Population and Housing $(\mathrm{ZCPH})$, the pregnancyrelated mortality ratio among girls aged $15-19$ years is $80 \%$ higher than among those aged 20-24 [50]. Adolescent childbearing rates are much higher in rural than urban areas, and higher among girls who are out-of-school compared to those still attending (36\% vs $5 \%$ at age 17 in rural areas) (unpublished data from $2010 \mathrm{ZCPH}$ ).

In preparation for this trial, we conducted formative research to explore contributors to early childbearing, marriage and school dropout. In-depth interviews (IDIs) and focus group discussions (FGDs) were conducted with girls, parents, teachers, health workers and community leaders in December 2014 and January 2015. Poverty was raised as a primary reason for early childbearing, early marriage and school dropout; girls mentioned a desire for gifts/money as an important reason for engaging in sexual relations; and parents put pressure on their daughters to get married to secure their daughters economically and to obtain the bride price. Moreover, many families could not afford uniforms or school fees at secondary school level. Other factors leading to early pregnancy were misconceptions linked to contraception, e.g. that girls could end up as infertile if they use hormonal contraception before their first pregnancy, social barriers to seeking contraception, and school dropout. Girls who have dropped out of school were regarded as ready for marriage after menarche. The SRH curriculum in Zambian schools is comprehensive on paper [51], but the interviews with teachers indicated that in practice a high proportion of them tend to focus on sexual abstinence as the only way to avoid pregnancy or sexually transmitted infections (STIs), including HIV. Hence misconceptions about modern contraceptives can prevail. Pregnancy was also described as leading to school dropout and marriage, although some girls reenter school after having given birth.

Since early pregnancy and marriage in Zambia have multiple causes, our contextual assessment implies that it is likely that a programme that targets several contributing factors will have a greater effect than a single focus intervention. This is in line with the existing literature, which has increasingly recognized that multicomponent interventions are needed to achieve a substantial impact on complex issues such as adolescent childbearing, early marriage and school dropout [52-55]. Further, as long as a high proportion of girls never enrol in secondary school, preventing early marriage and childbearing also needs to reach out-ofschool girls. Informed by our literature review, the formative research, discussions with key stakeholders such as the Ministry of General Education (MoGE), the Ministry of Community Development and Mother and Child Health $(\mathrm{MCDMCH})$ and local stakeholders, we developed an intervention package that targets what we identified as the main causes of early pregnancy: (1) an economic component targeting poverty and school dropout, with the aim to increase school attendance and secondary school enrolment, and to reduce parental pressure for early marriage and girls' dependence on having a boyfriend to receive basic goods; and (2) a community component, including a youth club, that aims to enhance SRH knowledge and skills, and perceived supportive community norms regarding pursuit of education and postponement of pregnancy and marriage. Our hypothesis is that the timing of support is important, and payment of school fees, which reduces the cost of schooling, may be decisive at stages when children approach transition points in the education system, e.g. between primary and secondary school, when costs would otherwise increase.

\section{Objectives}

Primary objectives:

1. To measure the effectiveness of a combined economic and community intervention on childbearing within 8 months of the end of the intervention period.

2. To measure the effectiveness of economic support alone and of a combined economic and community intervention on childbearing before the 18th birthday among girls. 
3. To measure the effectiveness of economic support alone and of a combined economic and community intervention on the proportion of girls who sit for the grade 9 exam.

Secondary objectives:

To measure the effectiveness among girls of economic support alone and of a combined economic and community intervention on:

1. Pregnancy and childbearing within 2 years of the end of the intervention period

2. Pregnancy and childbearing before the 16th birthday

3. Pregnancy before the 18 th birthday

4. Marriage before the 16th and 18th birthday

5. Socioeconomic inequality in childbearing and marriage before the 18th birthday

6. Enrolment in grade 8 and 10, school attendance, and grade 9 exam scores

7. Socioeconomic inequality in participation in the grade 9 exam

8. Knowledge and experiences related to sexual and reproductive health, including modern contraceptives

9. Attitudes and perceived community norms related to: the value of educating girls, early marriage, modern contraceptive use, and adolescent pregnancy

10.Employment status

\section{Methods}

\section{Study design}

The intervention packages will be examined in a cluster randomized controlled trial with two intervention arms and one control arm (Fig. 1). The randomization units will be basic schools and their surrounding communities. (Basic schools offer grades 1-9. Primary school in Zambia comprises grade $1-7$ and grades 8 and 9 are referred to as junior secondary school.) The selected schools are at least $8 \mathrm{~km}$ apart from each other.

\section{Study setting and participant population}

The participants will be girls enrolled in grade 7 in 2016 in rural basic schools in 12 districts in Zambia: Kalomo, Choma, Pemba, Monze, Mazabuka, Chikankata, Chisamba, Chibombo, Kabwe, Kapiri Mposhi, Mkushi, and Luano. These districts were selected as they have medium school dropout rates, and adolescent marriage and childbearing are common. All girls enrolled in grade 7, including anyone who is already married or has children, will be eligible to participate. Girls who drop out of school after they have been recruited will still be followed up and can continue to receive the interventions.

\section{Community sensitization and acceptance}

To achieve community acceptance, chiefs, headmen, religious - and informal - leaders, headmasters and Parent Teacher Association (PTA) committee members were oriented and asked to support the trial activities before the recruitment was initiated. Local radio has also been used for community sensitization. Communities and schools were informed that any individual school in which $>15 \%$ of the girls did not assent would not be included in the trial.

\section{Interventions}

The interventions will be launched in September 2016 and will last for 27 months, until November 2018 (the end of the academic year when the girls who attend school are expected to complete grade 9). The intervention may be extended one more year, given supplementary funding. In all the study arms, girls will be offered writing materials (exercise books, pencils and pens) as an incentive to participate. Apart from this, only standard school and health services will be offered in the control arm.

\section{Economic support}

In the intervention arms, girls and their parents/guardians will be offered economic support, consisting of a monthly cash transfer for the girl (ZMW 30), an annual cash grant to her parents/guardians (ZMW 350/year) and payment of school fees for girls who enrol in grade 8 and 9 (up to ZMW 500 per term). The support package targets the key actors in the decisions leading to early pregnancy and marriage. Cash transfers target the poverty dimension, by making it somewhat less urgent for the guardians that the girl gets married and for the girl to receive gifts from a boyfriend.

The payment of school fees will be made directly to the school bank account for girls who get a place in grade 8 and 9 . The money for the girls and the guardians will be disbursed by a cash transfer committee consisting of a teacher and two parents from the PTA committee. At least two of the cash transfer committee members will be present during disbursement to witness that the right persons receive the cash. Girls will also be asked in every follow-up contact how much money they have received, and all participants will be encouraged to contact the study team if they do not receive the right amount.

There will be no age limit for the economic support for girls who are in school, but for girls who drop out of school, it will stop after the 18th birthday. The economic support will also be discontinued for girls who do not participate in the follow-up contacts.

\section{Community dialogue}

The second intervention arm will combine the economic support with a community-oriented intervention consisting 


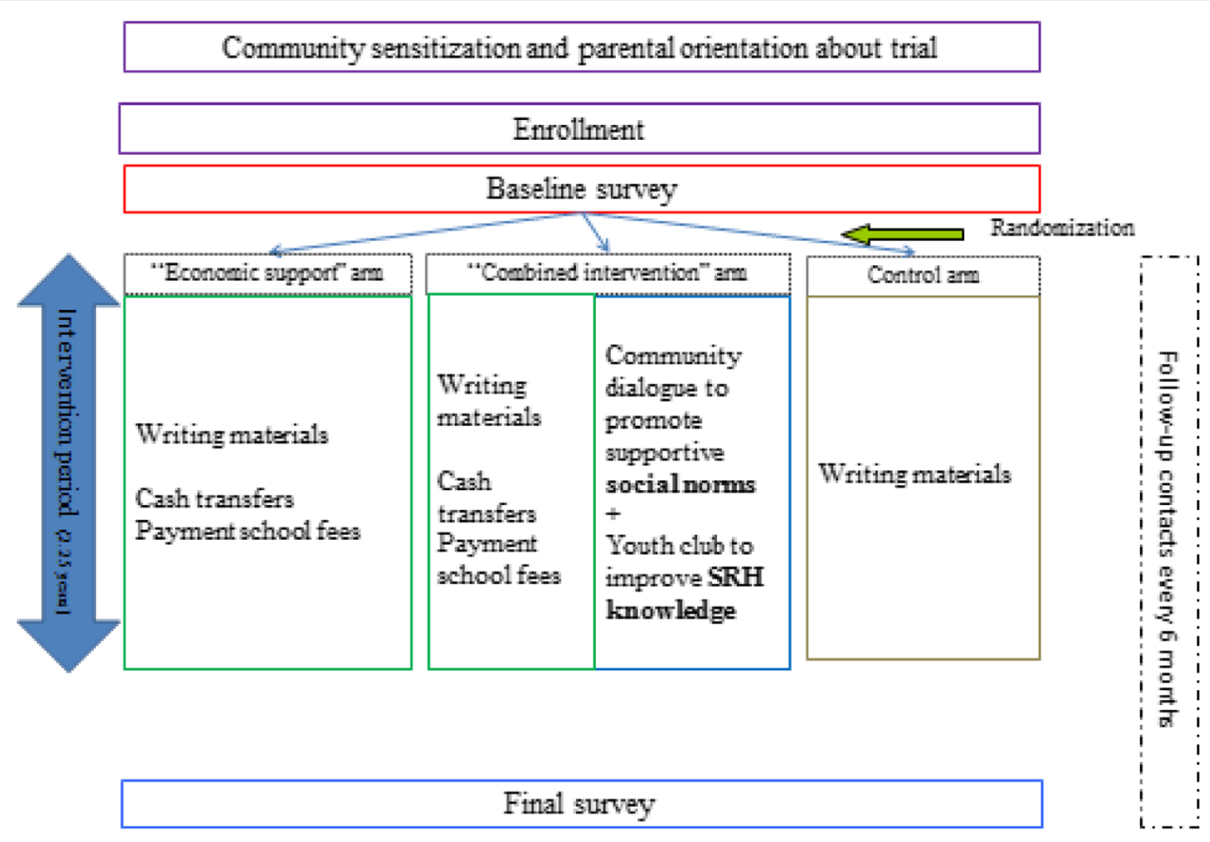

Fig. 1 Flow chart of trial

of (1) community and parent meetings employing a community dialogue approach in promoting supportive community norms around education for girls and postponement of early marriage and early childbearing; and (2) establishment of youth clubs in order to provide comprehensive sexual and reproductive health education among in- and out-of-school adolescent girls and boys.

Girls participating in the trial and boys who attend grade 7 in 2016 in the randomly selected schools will be invited to participate in a youth club every fortnight during the school terms, and they will all be welcome to continue in the youth club even if they quit school. The meetings will include interactive discussions on education, early marriage, the risks of early pregnancy, gender roles, and sexual and reproductive health, including myths around modern contraceptives. We will test a model where a teacher is linked with a community health assistant (CHAs) or a community health worker (CHW) to run the youth club together. Meetings will be held to inform parents about the content of the youth club sessions. Before the intervention is launched, the selected teachers and CHAs/CHWs will be given a 5-day training which will focus on the SRH curriculum, facilitation techniques and approaches to community mobilization. Refresher training will be held halfway during the intervention period. In addition, orientation meetings will be held to inform other healthcare workers in the catchment area of the schools about the project and the importance of providing youth-friendly health services.

For each combined intervention cluster, two young ( $<20$ years) unmarried women from the local community will be selected as youth peer educators. The role of the peer educators will be to mobilize girls and boys to come to youth club meetings.

Meetings with the community at large will be organized bimonthly. These meetings will be conducted using a dialogue approach [56] and will discuss topics such as the value of education, and the risks and benefits of early childbearing. Films or role plays will be used to start discussions.

\section{Outcomes}

The outcomes, measurement tools, measurement times and validation tools are listed in Table 1 .

\section{Sample size}

We used PASS 14 (NCSS Statistical Software, Kaysville, UT, USA) to calculate sample size required for a cluster randomized trial with the primary outcomes "incidence of births within 8 months of the end of the intervention period", "incidence of births before girls' 18th birthday" and "proportion of girls who sit for the grade 9 exam".

We used the 2010 census estimates of the percentages reporting ever giving birth in the study districts to estimate the incidence of childbearing in the control arm: $2 \%$ at the average age of 14.5 years, $4 \%$ at 15.5 years, $9.5 \%$ at 16.5 years, $22 \%$ at 17.5 years, and $35 \%$ at 18.5 years. The interventions will not affect childbearing until approximately 9 months after the start of the intervention, when the average age will be 15 . We assume that $3 \%$ of the girls will have given birth before any effects of the interventions can be seen. The other assumptions 
Table 1 Outcomes, measurement tools, measurement times and validation tools

\begin{tabular}{|c|c|c|c|c|}
\hline & & Measurement tool & $\begin{array}{l}\text { Months from recruitment } \\
\text { to measurement }\end{array}$ & Validation \\
\hline \multirow[t]{3}{*}{ Primary outcomes measures } & $\begin{array}{l}\text { Incidence of births within } 8 \text { months } \\
\text { of the end of the intervention period }\end{array}$ & $\begin{array}{l}\text { Follow-up contact } \\
\text { questionnaire (FupQ) }\end{array}$ & $42-44$ & $\begin{array}{l}\text { FinQ } 54-56 \text { months } \\
\text { after recruitment }\end{array}$ \\
\hline & Incidence of births before girls' 18th birthday & Final questionnaire (FinQ) & $54-56$ & \\
\hline & $\begin{array}{l}\text { Proportion of girls who sit for the } \\
\text { grade } 9 \text { exam }\end{array}$ & FinQ & $54-56$ & $\begin{array}{l}\text { Exam registers from District } \\
\text { Education Board Secretary } \\
\text { (DEBS) } 54-56 \text { months } \\
\text { after recruitment }\end{array}$ \\
\hline \multirow{22}{*}{$\begin{array}{l}\text { Secondary outcome } \\
\text { measures }\end{array}$} & Pregnancy and childbearing & & & \\
\hline & $\begin{array}{l}\text { Incidence of pregnancies among } \\
\text { girls within } 2 \text { years of the end of } \\
\text { the intervention period }\end{array}$ & FinQ & $54-56$ & \\
\hline & $\begin{array}{l}\text { Incidence of births among girls } \\
\text { within } 2 \text { years of the end of the } \\
\text { intervention period }\end{array}$ & FinQ & $54-56$ & \\
\hline & $\begin{array}{l}\text { Incidence of pregnancies before } \\
\text { girls' 16th birthday }\end{array}$ & FinQ & $54-56$ & $\begin{array}{l}\text { FupQ } 24-48 \text { months } \\
\text { after recruitment }\end{array}$ \\
\hline & $\begin{array}{l}\text { Incidence of births before girls' } \\
\text { 16th birthday }\end{array}$ & FinQ & $54-56$ & $\begin{array}{l}\text { FupQ } 24-48 \text { months } \\
\text { after recruitment }\end{array}$ \\
\hline & $\begin{array}{l}\text { Incidence of pregnancies before } \\
\text { girls' 18th birthday }\end{array}$ & FinQ & $54-56$ & \\
\hline & $\begin{array}{l}\text { Socioeconomic inequality in proportion } \\
\text { of girls who have given birth before } \\
\text { their 18th birthday }\end{array}$ & FinQ & $54-56$ & \\
\hline & Marriage & & & \\
\hline & $\begin{array}{l}\text { Proportion of girls that are married } \\
\text { and/or cohabiting before their } \\
\text { 16th birthday }\end{array}$ & FinQ & $54-56$ & $\begin{array}{l}\text { FupQ 6-48 months after } \\
\text { recruitment }\end{array}$ \\
\hline & $\begin{array}{l}\text { Proportion of girls that are married } \\
\text { and/or cohabiting before their } \\
\text { 18th birthday }\end{array}$ & FinQ & $54-56$ & \\
\hline & $\begin{array}{l}\text { Socioeconomic inequality in proportion } \\
\text { of girls that are married/cohabiting } \\
\text { before their 18th birthday }\end{array}$ & FinQ & $54-56$ & \\
\hline & School-related & & & \\
\hline & Proportion of girls who enrol in grade 8 & FupQ & $12-14$ & School registers \\
\hline & $\begin{array}{l}\text { Socioeconomic inequality in participation } \\
\text { in the grade } 9 \text { exam among girls }\end{array}$ & FinQ & $54-56$ & $\begin{array}{l}\text { Exam registers December } \\
2018 \text { and } 2020\end{array}$ \\
\hline & Proportion of girls who enrol in grade 10 & FupQ & $36-38$ & School registers \\
\hline & $\begin{array}{l}\text { Average examination scores of girls } \\
\text { from grade } 9 \text { in English, mathematics } \\
\text { and science }\end{array}$ & $\begin{array}{l}\text { Exam results from District } \\
\text { Education Board Secretary } \\
\text { (DEBS) }\end{array}$ & Dec 2018 & \\
\hline & School attendance of girls in grade 8 & School registers & Dec 2018 & $\begin{array}{l}\text { FupQ } 12-14 \text {, and } 18-20 \\
\text { months after recruitment }\end{array}$ \\
\hline & School attendance of girls in grade 9 & School registers & Dec 2018 & $\begin{array}{l}\text { FupQ } 24-26 \text { and } 30-32 \\
\text { months after recruitment }\end{array}$ \\
\hline & Other reproductive health outcomes & & & \\
\hline & $\begin{array}{l}\text { Proportion of adolescent girls who have } \\
\text { been sexually active in last } 4 \text { weeks }\end{array}$ & FupQ & $30-32$ & \\
\hline & $\begin{array}{l}\text { Proportion of adolescent girls currently } \\
\text { using modern contraceptives }\end{array}$ & FupQ & $30-32$ & \\
\hline & $\begin{array}{l}\text { Knowledge of modern contraceptives } \\
\text { among adolescent girls }\end{array}$ & FupQ & $30-32$ & \\
\hline
\end{tabular}


Table 1 Outcomes, measurement tools, measurement times and validation tools (Continued)

\begin{tabular}{|c|c|c|}
\hline \multicolumn{3}{|l|}{ Perceived community norms } \\
\hline $\begin{array}{l}\text { Perceived community norms regarding } \\
\text { modern contraceptive use among } \\
\text { unmarried adolescent girls }\end{array}$ & FupQ & $30-32$ \\
\hline $\begin{array}{l}\text { Perceived community norms regarding } \\
\text { early marriage among girls }\end{array}$ & FupQ & $30-32$ \\
\hline $\begin{array}{l}\text { Perceived community norms regarding } \\
\text { adolescent pregnancy among girls }\end{array}$ & FupQ & $30-32$ \\
\hline $\begin{array}{l}\text { Perceived community norms regarding } \\
\text { education among girls }\end{array}$ & FupQ & $30-32$ \\
\hline \multicolumn{3}{|l|}{ Other } \\
\hline $\begin{array}{l}\text { Proportion of girls currently employed } \\
\text { or self-employed }\end{array}$ & FinQ & $54-56$ \\
\hline
\end{tabular}

for the sample sizes required to detect differences for the primary outcomes "incidence of births before girls' 18th birthday" and "incidence of births within 8 months of the end of the intervention period" are presented in Tables 2 and 3. We find (using twosided tests) that with 63 clusters in each of the intervention arms and 31 in the control arm we will have $70 \%$ power to detect the assumed difference between the economic and the combined interventions, $80 \%$ power for the comparison of the economic intervention versus the control arm, and $>95 \%$ power to detect the assumed difference between the combined intervention versus the control arm for the outcome "incidence of births before girls' 18th birthday". For the outcome "incidence of births within 8 months of the end of the intervention period" we will have $>90 \%$ power for the comparison of the combined intervention versus the control group.

Table 2 Assumptions for sample size required to measure the primary outcome "incidence of births before girls" 18th birthday"

\begin{tabular}{|c|c|c|}
\hline Parameter & Assumed level & Comment \\
\hline Incidence of births before girls' 18th birthday & 0.08 & $\begin{array}{l}\text { We assume that } 27 \% \text { of girls in the control arm will have given } \\
\text { birth before their } 18 \text { th birthday. This corresponds to an average } \\
\text { incidence rate of }(27 \%-3 \%)=8 \% \text { per year over the average 3-year } \\
\text { period (from the time the average age is } 15 \text { ). }\end{array}$ \\
\hline Effectiveness of combined intervention vs control & $-40 \%$ & $\begin{array}{l}\text { i.e. the incidence in combined intervention arm assumed to be } \\
0.048\end{array}$ \\
\hline Effectiveness (i.e. (1-RR) $\times 100$ of economic intervention vs control & $-25 \%$ & i.e. the incidence in economic intervention arm assumed to be 0.06 \\
\hline $\begin{array}{l}\text { Effectiveness of combined intervention vs economic } \\
\text { intervention }\end{array}$ & $-20 \%$ & $\begin{array}{l}\text { The combined intervention will offer }[1-(0.0 .048 / 0.06)] \text {, i.e. } 20 \% \text { more } \\
\text { relative protection than the economic intervention alone. }\end{array}$ \\
\hline Cluster size & 28 & $\begin{array}{l}\text { Average number of girls in grade } 7 \text { in the selected schools is } 31 \text {. } \\
\text { If we assume that up to } 10 \% \text { may be lost to follow-up by the time } \\
\text { of measuring the outcome, the average cluster size will be } 28\end{array}$ \\
\hline Person years per cluster & 84 & $\begin{array}{l}\text { If } 28 \text { participants are followed up for } 3 \text { years on average, } \\
\text { person years per cluster are } 84 \text {. }\end{array}$ \\
\hline K & 0.15 & $\begin{array}{l}\text { The ICC was } 0.00737 \text { for "ever pregnant" after the intervention period } \\
\text { in the cash transfer trial in Malawi (estimate obtained from Sarah Baird). } \\
\text { This corresponds to } k=0.15 \text { when the total proportion who have } \\
\text { given birth by this time is } 0.27 \text {. }\end{array}$ \\
\hline
\end{tabular}

$\mathrm{Z}_{1}$

Power for comparison of economic intervention vs combined intervention

Power for comparison of economic intervention vs control
We need 63 clusters in each of the intervention arms to have $70 \%$ power to detect the assumed difference

We need 39 clusters in each arm to have $80 \%$ power to detect the assumed difference. The PASS power calculator for incidence rates does not allow for unequal trial arms, but the PASS function for proportions indicates that 63 economic and 31 control will give slightly higher power

We need 23 clusters in each arm to have 95\% power to detect the assumed difference. 
Table 3 Assumptions for sample size required to measure the primary outcome "incidence of births within 8 months of the end of the intervention period"

\begin{tabular}{|c|c|c|}
\hline Parameter & Assumed level & Comment \\
\hline Incidence of births in control group & 0.06 & $\begin{array}{l}\text { Eight months after the end of the intervention period } \\
\text { the girls will be on average } 17.1 \text { years and we assume } \\
\text { that } 15 \% \text { of them will have given birth. This corresponds } \\
\text { to an average incidence rate of }(15 \%-3 \%) / 2=6 \% \text { over } \\
\text { this } 2 \text {-year period. }\end{array}$ \\
\hline $\begin{array}{l}\text { Effectiveness of combined intervention vs } \\
\text { control }\end{array}$ & $-40 \%$ & $\begin{array}{l}\text { i.e. incidence in combined intervention arm assumed } \\
\text { to be } 0.036\end{array}$ \\
\hline Cluster size & 28 & $\begin{array}{l}\text { See assumptions for the outcome "incidence of births before } \\
\text { girls' 18th birthday" }\end{array}$ \\
\hline Person years per cluster & 56 & $\begin{array}{l}\text { If } 28 \text { participants are followed up for } 2 \text { years, there will be } \\
56 \text { person years }\end{array}$ \\
\hline k & 0.20 & $\begin{array}{l}\text { The ICC was } 0.00737 \text { for "ever pregnant" after the intervention period in the cash transfer } \\
\text { trial in Malawi. This corresponds to } k=0.20 \text { when the total } \\
\text { proportion who have given birth by this time is } 0.15\end{array}$ \\
\hline$Z_{1}$ (acceptable alpha error level) & 1.96 & \\
\hline $\begin{array}{l}\text { Power for comparison of combined } \\
\text { intervention vs control }\end{array}$ & $90 \%$ & $\begin{array}{l}\text { We need } 36 \text { combined clusters vs } 36 \text { control clusters to have } 90 \% \\
\text { power detect the assumed difference. The PASS function for } \\
\text { proportions indicates that with } 63 \text { combined clusters, we will have } \\
>90 \% \text { power with } 30 \text { control clusters. }\end{array}$ \\
\hline
\end{tabular}

The percentage of girls enrolled in grade 7 who sat for the grade 9 exam was approximately 50\% in 2012. In 2015 the Ministry of General Education (MoGE) removed the previous entry requirements for grade 8 in Central province and all pupils who sit for the grade 7 exam in Chibombo, Chisamba, Kapiri Mposhi, Kabwe, Mkushi and Luano will be admitted to grade 8 . To be enrolled they will have to pay school fees. The percentage who enrols in grade 8 is very likely to increase due to this policy change. This policy has not been introduced in Southern province (where the districts Kalomo, Choma, Pemba, Monze, Mazabuka and Chikankata are located). We have assumed that the percentage will be $70 \%$ overall in the control arm. See Table 4 for the other assumptions. With 30 clusters in each arm, we will have $95 \%$ power or more for each of the three comparisons.

Taking the largest of these sample sizes, we need 63 clusters in each of the intervention arms. Since we expect larger differences between each of the intervention arms and the control arm than between the two intervention arms themselves we can reduce the total number of clusters by allowing for a lower sample size in the control arm. Thus we will include at least 63 economic intervention clusters, 63 combined intervention clusters and 31 control clusters, i.e. 157 clusters with a total of $31 \times 157=4867$ or approximately 4900 girls.

\section{Recruitment}

The recruitment started in March and will be completed in July 2016 (Fig. 2: SPIRIT figure). The parents/guardians of girls in grade 7 are invited to an information meeting. If their daughter is $<18$ years, they are asked to give consent to her participation in the trial (Additional file 1). After the consent is obtained, girls are informed and asked to assent by a research assistant (Additional file 2). Any girl aged $\geq 18$ years is informed directly and asked to consent (Additional file 3). Those who consent/assent and participate in the baseline survey interview are enrolled.

\section{Randomization and masking}

Randomization will take place in July 2016, after recruitment is completed. We will organize six randomization ceremonies, each for two districts, where the schools will be stratified by district and randomly allocated to the three arms. Before each ceremony, 1000 allocations will be computer-generated by an independent scientist from the Centre for Interventions Science in Maternal and Child health (CISMAC), and each allocation will be numbered. Officials from the study districts, chiefs, head teachers and PTA members of the trial schools will be invited to be present. Community members will be welcome too. Tickets with numbers corresponding to a specific allocation will be drawn from a box.

There will be no blinding of participants, but the team doing the final survey will be independent from the intervention delivery and they will be unaware of the intervention status of respondents. Biannual follow-up contacts with the participants and the final surveys will be conducted by research assistants who are independent from the intervention implementation team.

\section{Data collection}

All the tools have been translated to Tonga, Nyanja, Bemba and Lenje, the major local languages in the study 
Table 4 Assumptions for sample size required to measure the primary outcome "proportion of girls who sit for the grade 9 exam"

\begin{tabular}{|c|c|c|}
\hline Parameter & Assumed level & Comment \\
\hline Proportion of girls who sit for the grade 9 exam in control arm & 0.70 & \\
\hline Effectiveness of combined intervention vs control & $+26.5 \%$ & $\begin{array}{l}\text { i.e. proportion completing in combined intervention } \\
\text { arm assumed to be } 0.886\end{array}$ \\
\hline Effectiveness (i.e. (1-RR) $\times 100$ of economic intervention vs control & $+15 \%$ & $\begin{array}{l}\text { i.e. proportion completing in economic intervention } \\
\text { arm assumed to be } 0.805\end{array}$ \\
\hline Effectiveness of combined intervention vs economic intervention & $+10 \%$ & $\begin{array}{l}\text { The combined intervention will offer a }[1+(0.886 / 0.805)] \text {, } \\
\text { i.e. } 10 \% \text { relative increase compared to the economic } \\
\text { intervention alone. }\end{array}$ \\
\hline Cluster size & 28 & $\begin{array}{l}\text { See assumptions for the outcome "incidence of births } \\
\text { before girls' 18th birthday" }\end{array}$ \\
\hline ICC & 0.02 & $\begin{array}{l}\text { We have no information on the ICC for this outcome but } \\
\text { have assumed it to be higher than for pregnancy }\end{array}$ \\
\hline$Z_{1}$ & 1.96 & \\
\hline Power for comparison of economic intervention vs combined intervention & $95 \%$ & $\begin{array}{l}\text { We need } 29 \text { clusters in each of the intervention arms to } \\
\text { have } 95 \% \text { power to detect the assumed difference }\end{array}$ \\
\hline Power for comparison of economic intervention vs control & $95 \%$ & $\begin{array}{l}\text { We need } 24 \text { clusters in each of the arms to have } 95 \% \\
\text { power to detect the assumed difference }\end{array}$ \\
\hline Power for comparison of combined intervention vs control & $>95 \%$ & $\begin{array}{l}\text { We need } 7 \text { clusters in each arm to have } 95 \% \text { power to } \\
\text { detect the assumed difference }\end{array}$ \\
\hline
\end{tabular}

districts, and then back-translated to ensure that the content is maintained. Interviews are conducted in English or one of these four local languages, depending on the preference of the participant. The main data collection tools are described in Table 5.

We will collect information about the location and size of schools that are excluded due to suboptimal participation.

\section{Data management and quality assurance}

All the quantitative tools have been piloted to ensure that the questions and the translations are relevant and comprehensible. Data from interviews will be captured electronically using tablets and CommCare (https://www.commcarehq.org/home/) as our data management software. The forms have inbuilt checkand-skip rules to minimize data entry errors.

Names and telephone numbers and addresses will not be recorded in the same forms as sensitive data. Each participant will be given a unique identifier, and this number will be used when storing forms. Only the Data Manager, the Principal Investigator and the CoPrincipal Investigator will have access to the personal identifiers. All data will be saved on password-protected computers and tablets. The database is hosted by Dimagi (http://www.dimagi.com/), and weekly downloads of data

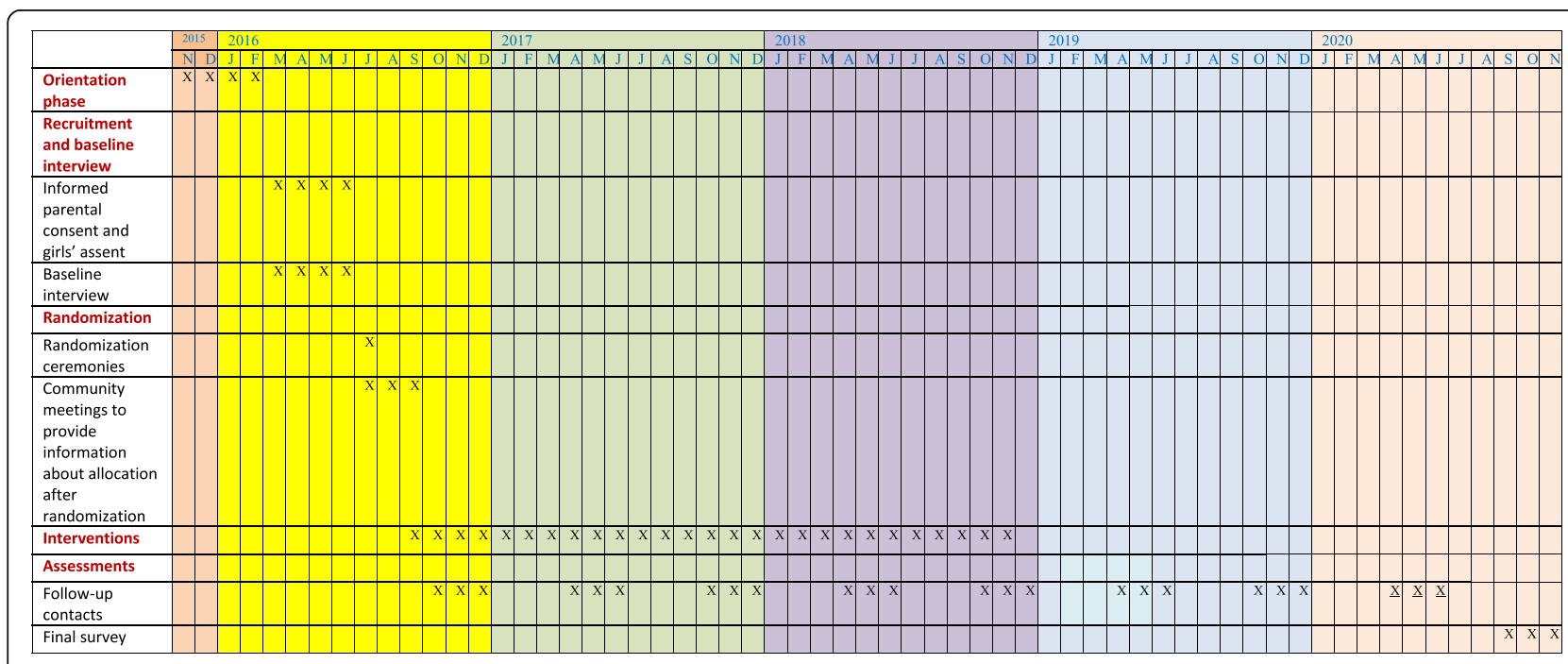

Fig. 2 SPIRIT figure. Schedule of enrolment, interventions, and assessments 
Table 5 Data collection elements

\begin{tabular}{|c|c|}
\hline Activity & Description \\
\hline Baseline survey & $\begin{array}{l}\text { Trained research assistants conduct baseline face-to-face interviews with girls at school immediately after recruitment. } \\
\text { The structured questionnaires cover questions on date of birth (Additional file 4), marital status, previous childbearing, } \\
\text { household assets, perceived community norms related to education, early marriage and childbearing, and knowledge } \\
\text { about SRH and contraceptives (Additional file 5). Mobile phone numbers of participating girls (if any), parents/guardians } \\
\text { and close relatives or neighbours are recorded for use in the follow-up interviews (Additional files } 4 \text { and 6). Brief } \\
\text { interviews are also done with the girls' guardians about the educational attainment of the girls' parents and head } \\
\text { of household (Additional file 6). }\end{array}$ \\
\hline Follow-up contacts & $\begin{array}{l}\text { All the girls in the trial will be contacted every } 6 \text { months via phone to update contact information and ask } \\
\text { questions about school attendance, employment, marital status and childbearing. Girls in the intervention arms will } \\
\text { be asked whether they have received the cash transfers and/or participated in the youth club meetings. To monitor } \\
\text { adverse events, girls will also be asked about hospitalizations and whether they have experienced problems due to } \\
\text { their participation in the trial. If the girl cannot be reached via phone, field-based research assistants will attempt to } \\
\text { meet and interview her (Additional files } 7,8 \text {, and 9). }\end{array}$ \\
\hline Qualitative process evaluation & $\begin{array}{l}\text { IDIs and FGDs will be conducted to explore experiences with the various intervention components of purposively } \\
\text { selected girls, boys, parents/guardians, and other community members. }\end{array}$ \\
\hline Quantitative process evaluation & $\begin{array}{l}\text { We will collect attendance lists from each youth club meeting and reports with counts of how many persons show } \\
\text { up at all parent - and community- meetings. Information on who has received cash transfers and payment of } \\
\text { school fees will be recorded. We will collect data on school performance, school attendance and exam results of all } \\
\text { study participants from school registers. }\end{array}$ \\
\hline Final follow-up survey & $\begin{array}{l}\text { A phone-based final survey will be conducted at the end of } 2020 \text { when the majority of the girls will be above } \\
18 \text { years. The questionnaire will include measurements of the primary and secondary outcomes. If the girl cannot } \\
\text { be reached via phone, field-based research assistants will attempt to meet her face-to-face. If additional funding is } \\
\text { secured we will consider doing these interviews face-to-face instead. }\end{array}$ \\
\hline
\end{tabular}

FGD focus group discussion, IDI in-depth interview, $S R H$ sexual and reproductive health

are done to a secure server owned by the University of Bergen. When the trial is completed, all personal identifiers will be deleted.

In the qualitative process evaluation, we will seek permission to audio record the individual interviews and focus group discussions using digital recorders. The recordings will be transcribed and translated verbatim. A senior researcher will review the transcripts to ensure that they contain word by word transcriptions and translations that retain original meanings, with a particular caution to retain culturally embedded content.

\section{Statistical methods}

The data will be analysed with Stata 14 (StataCorp, College Station, TX, USA) software. The outcomes will be captured in time-to-event, binary and continuous variables. Descriptive statistics will be used to describe continuous and categorical variables. We will compare outcomes between the three arms: the economic arm versus the control arm, the combined arm versus the control arm, and the economic arm versus the combined intervention arm. Analyses will be by intention-to-treat (ITT).

The childbearing outcomes will be measured based on the participants' responses to the questions "Have you ever given birth to a baby who was born alive?", "Have you ever given birth to a baby who was born dead?", "If yes, on which date and which year did you give birth?" and "How many months pregnant were you when you gave birth?". We will count stillbirths after 6 months or 28 weeks pregnancy as births. Pregnancies conceived before the intervention starts will be excluded from the analysis of effects on childbearing and pregnancy.

For the incidence measures of childbearing, survival analysis using Cox regression will be employed. Timeon-study will be used as the timescale when measuring outcomes occurring within 8 months or 2 years of the end of the intervention period, and age will be the timescale when measuring outcomes before the 16th and 18th birthdays. Proportions will be compared using generalized estimating equations (GEE) with a log link. The ICC will be reported for all primary and secondary outcomes. Any remaining imbalances of predictors of the outcomes after randomization will be adjusted for in the regression models. In all models, we will also adjust for potential confounders such as age. When there are missing values, we will explore whether data is missing completely at random (MCAR) or whether data is missing at random (MAR). If MCAR and MAR are satisfied, we will do complete case analysis and explore multiple imputation using Stata software.

Equity effects will be examined by comparing distributions of primary and secondary outcomes between wealth tertiles and educational tertiles within each trial arm. Inequality will also be analysed using the concentration index.

Further details will be provided in a separate statistical analysis plan.

\section{Qualitative data analysis}

The content of the qualitative data from IDIs and FGDs will be explored on the same day as interviews and 
FGDs are done, and the researchers will adjust the interview guides to enhance their relevance. The transcribed and translated texts will be entered into QSR NVIVO 10. The analysis of the interviews, FGDs, open-ended questions from $\log$ forms and observations will follow a classical approach employing Malterud's 'Systematic text condensation' [57], a descriptive and explorative method for thematic cross-case analysis drawing upon Giorgi's psychological phenomenological analysis. Systematic text condensation consists of the following four steps: (1) total impression; (2) identifying and sorting meaning units; (3) condensation; (4) synthesizing.

\section{Data monitoring}

A Data Monitoring Committee (DMC) with three members has been established. The committee will be independent of the project management team. The committee will advise on study modification or termination based on its reviews of data. A charter for the DMC has been developed and can be obtained from the authors. The $\mathrm{DMC}$ will review the follow-up rates from the 6-monthly surveys.

\section{Benefits and harms}

Participants in the intervention arms will benefit from what the intervention packages offer. If the intervention packages are found to have a positive impact and the government consequently introduces a similar programme, adolescents and their families in many communities may benefit.

Unanticipated problems or adverse events such as deaths and hospitalizations and whether these are likely to be related to the trial, will be recorded and reported to the ethics committees (UNZABREC and REK-West) and the Data Monitoring Committee.

\section{Auditing}

All community and parent meetings will be captured photographically if those present consent, and a report form will be filled in that automatically captures GPS coordinates to verify the place and time of the meetings. Youth club and community meetings will be regularly monitored by the research team to observe the quality of the delivery of the intervention.

An external expert assigned by CISMAC will conduct annual monitoring visits during study implementation. If challenges are detected, an action plan to address these will be prepared.

\section{Adaptions}

The intervention will be adaptive, i.e. elements in the intervention package delivered to a cluster will be modified if obstacles to the implementation of the intervention are encountered, the participation is suboptimal or if important changes occur. When the Project Management
Team believes it is important to make substantial adaptions of the trial design, CISMAC will be asked to critically consider whether the proposed adaptions are necessary and sufficient. Important protocol modifications will be reported to the DMC, UNZABREC and REK-West, and registered in ISRCTN and clinicaltrials.gov.

\section{Access to data}

The data will be owned by the University of Bergen and the University of Zambia. Project management team members will have access to the data. Other requests for access will be considered after 3 years of trial completion.

\section{Dissemination plan}

This protocol was written following the Standard Protocol Items: Recommendations for Interventional trials (SPIRIT) checklist (see Additional file 10). Dissemination of the research findings will be done through scientific articles in peer-reviewed journals, reports and presentations at national and international academic- and policy-related conferences. We will report findings according to the Consolidated Standards of Reporting Trials (CONSORT) guidelines. Protocol modifications will be reported when disseminating findings. Authorship of scientific articles emerging from the study will be decided upon following guidelines from the International Committee of Medical Journal Editors.

We have established an advisory group with representatives from the MoGE, Ministry of Health $(\mathrm{MoH})$, Ministry of Gender, and the Ministry of Traditional Affairs. We will share and discuss research findings with the group and other key stakeholders in Zambia and the study communities.

\section{Discussion}

Relevance and potential for impact

This trial will examine the effectiveness of two intervention components that have potential for scale-up and are in line with political priorities in Zambia. A welfare programme in the form of cash transfers is a particularly relevant approach to reduce the effects of poverty as the government is already implementing similar programmes. With payment of schools fees at secondary level, we will mimic what may happen if secondary education becomes free, like the previous government declared that they aimed to achieve [58]. The community component will examine the effects of a SRH curriculum that is in line with the new CSRHE framework from the MoGE and which will be scaled up in all Zambian schools. The programme we will test differs from the government's CSRHE programme in that it will include youths that are out-of-school, and parents and the wider community will 
also be engaged in a dialogue around the project's thematic focus to enhance community support to postpone childbearing and marriage and extend the period of staying in school for girls. A robust evaluation of these interventions is in line with the World Health Organization's recommendations for research on programmes to prevent early childbearing and marriage [10].

It seems plausible that the bigger the economic support is and the more intense the community intervention is, the stronger the impact may be. However, we have attempted to strike a balance between the scale and intensity of the intervention on the one hand and the wish to establish a programme that is feasible to implement and scale up. The cash transfers that will be offered amount to approximately the same per year as poor families receive through the government's 'Social Cash Transfer' scheme and are likely to be within the range that the government may consider if it were to implement a cash transfer programme for adolescent girls. This amount is estimated to be sufficient to pay for a school uniform and other school materials, and the combination of the cash transfers and payment of school fees will thus make schooling essentially free of cost for the family of an adolescent girl. Regarding the intensity of the community components, we have opted for biweekly meetings to ensure fairly frequent meetings while avoiding adding a huge additional work burden on teachers and $\mathrm{CHAs} / \mathrm{CHWs}$.

The sample size calculation has been based on an assumption that the impact of the interventions will be of more or less the same magnitude 2 years after the end of the intervention as at the end of the intervention period. Evaluations of cash transfer programmes have previously indicated that the effects of the cash transfers may continue for a few years after the intervention has come to an end, and in some cases, long-term impact has been found [22]. However, long-term effects may depend on changes in norms taking place [27]. For the community component we expect that it will take some time for community norms to change, but we assume that if normative changes do take place, these will persist for some time after the end of the intervention programme. In fact, it is also possible that the effects strengthen over time, if the interventions initiate a positive process of social and economic change in the communities. However, it is difficult to predict whether this will actually be the case. We have thus included both a primary outcome that will measure the effects on childbirth from pregnancies conceived up to the end of the intervention period, and an outcome that will measure longer-term effects.

Adolescent pregnancy rates are particularly high among girls who have never attended school, and the earlier a girl drops out of school, the higher is the likelihood that she gets pregnant at an early age [49]. We will be recruiting girls enrolled in grade 7 and this obviously implies that we will miss vulnerable girls who do not reach that level of schooling. We have chosen to study the effects of intervening at the transition point between primary and secondary school due to cost and time considerations, but are mindful that we may underestimate the potential effects the interventions could have had if they were implemented at an earlier stage reaching a higher proportion of the most vulnerable participants.

\section{Bias and confounding}

We recognize that adolescence is a period in which many migrate to go to school in other areas, to seek work or to get married [59]. Migration can increase the risk of loss to follow-up of participants, and attrition can reduce the power to detect differences between the study arms, and it can lead to selection bias if those who are lost are different from those who remain in the study. We will attempt to minimize selection bias by providing incentives for follow-up contact interviews and by introducing additional incentives if we experience substantial differential post-randomization dropout, and by including girls who only consent to providing information during follow-up rounds but refuse to receive the intervention. Telephone-based follow-up is likely to be a more feasible method to keep in touch with participants than if we were to track them physically, and contact details will be updated as part of these regular follow-up contacts. In order to incentivize participants to respond to follow-up contacts, replying to these calls will be a prerequisite for receiving the economic support in the intervention arms, and girls in the control arm will be offered a small compensation (of approximately ZMW 20) as a token of appreciation of their time. Girls in the intervention arms will be offered the same compensation after the intervention period is over. We will also invest the necessary resources to physically track the girls if we cannot reach them by phone.

Reporting bias is also a potential risk since all the outcome measurements will be based on self-reports. We hope to minimize recall bias by contacting the participants every 6 months and asking them questions about school enrolment, pregnancy, childbirth and marriage. In addition, some of the self-reported measures can be validated against information from other sources such as school attendance registers and examination records. It is possible that the power to detect differences could be higher for pregnancy-focused measurements than birth measurements since these can capture pregnancies that end in spontaneous or induced abortion. However, many women will avoid reporting pregnancies that do not end in a live birth, and it seems logical that pregnancies are more likely to be under-reported than deliveries as the latter are more difficult to hide. Giving birth may also 
enhance a girl's social status. As the primary outcomes should be as valid measures of childbearing as possible, we have selected "given birth" although we recognize that there may be some under-reporting of births that ended with the death of the baby (e.g. stillbirths) as such deaths are associated with stigma [60]. We also risk that some girls may hesitate to report outcomes such as live births, marriage, sexual activity and school dropout due to fear of sanctions since they are aware that the study explicitly aims to prevent these outcomes. Underreporting is particularly problematic if it is differential between the study arms. We will attempt to reduce social desirability bias by asking sensitive questions towards the end of the interview when some degree of rapport has ideally been achieved, by emphasising that we would like them to give us information on all births, including stillbirths, that there will be full confidentiality, and that there will be no negative implications from the project if the girl drops out of school, gets married or pregnant.

Contamination is a potential risk in relation to the community component. Since some of the schools are only $8 \mathrm{~km}$ apart, some communities may have children in both the intervention and the control schools. It may moreover be difficult to prevent guardians and community members from the two other arms from attending community meetings in the combined intervention arm. We will aim to minimize contamination by restricting the youth club to pupils who are enrolled in grade 7 in the combined intervention schools at the start of 2016 and by employing intention-to-treat analysis.

\section{Conclusions}

As far as we are aware, this will be the first cluster RCT to measure the effect of a package combining economic support and a community component to prevent adolescent childbearing in a LMIC. The intervention components have been carefully selected to ensure they will be feasible and sustainable to implement. Increased schooling among adolescent girls is likely to empower them economically [61] and cognitively, and combined with postponed childbearing this can enable them to better protect the health of their children [17] and themselves and moreover increases the probability that their future children will complete secondary school [5]. The findings from this study will be highly relevant for programmes aiming to improve adolescent reproductive health in Zambia and in similar contexts.

\section{Trial status}

The trial was still recruiting participants at the time of submission of the manuscript.

\section{Endnotes}

${ }^{1}$ First conducted November 2013, updated in November 2014, using the search query (( pregnancy in adolescence [MeSH]) OR (Adolescent or teen or youth or youths or girls) AND (Pregnancy [MeSH] or pregnant* or birth* or childbirth OR marriage or Marriage [MeSH])) AND ((intervention or program or programme or trial or experiment or experimental) AND (random*) OR (Controlled Clinical Trial $[\mathrm{MeSH}]$ or Clinical Trial $[\mathrm{MeSH}]$ or Clinical Trial, Phase III [MeSH] or Randomized Controlled Trial $[\mathrm{MeSH}]))$ ).

${ }^{2}$ Medline, Embase, Web of Science, PsycINFO, ERIC, EconLit, Campbell collaboration, Cochrane, CINAHL, POPLINE, LILACS, African Index Medicus, Index Medicus for the Eastern Mediterranean Region, Global Development Finance, Economic Outlook Database, and World Bank e-library.

\section{Additional files}

Additional file 1: Information sheet and consent form for parents about the Research Initiative to Support the Empowerment of Girls (RISE). (PDF $425 \mathrm{~kb}$ )

Additional file 2: Information sheet and assent form for girls aged $<18$ years about the Research Initiative to Support the Empowerment of Girls (RISE). (PDF $426 \mathrm{~kb}$ )

Additional file 3: Information sheet and consent form for girls aged $\geq$ 18 years about the Research Initiative to Support the Empowerment of Girls (RISE). (PDF 427 kb)

Additional file 4: Case record form. (DOCX $25 \mathrm{~kb}$ )

Additional file 5: Baseline survey questionnaire 2016. (DOCX 56 kb)

Additional file 6: Parent/guardian questionnaire at time of giving consent. (DOCX $21 \mathrm{~kb}$ )

Additional file 7: Field-based follow-up contact questionnaire for control arm. (DOCX $39 \mathrm{~kb}$ )

Additional file 8: Field-based follow-up contact questionnaire for economic intervention arm. (DOCX $39 \mathrm{~kb}$ )

Additional file 9: Field-based follow-up contact questionnaire for combined intervention arm. (DOCX $40 \mathrm{~kb}$ )

Additional file 10: SPIRIT checklists with recommended items to address in a clinical trial protocol and related documents. (DOC $121 \mathrm{~kb}$ )

\section{Abbreviations}

CHA: Community health assistant; CHW: Community health worker; CRCT: Cluster randomized controlled trial; CSRHE: Comprehensive Sexual and Reproductive Health Education; DEBS: District Education Board Secretary; DMC: Data Monitoring Committee; FGD: Focus group discussion; FinQ: Final questionnaire; FupQ: Follow-up contact questionnaire; HIV: Human immunodeficiency virus; HSV-2: Herpes simplex virus type 2; IDI: In-depth interview; LMIC: Low- and middle-income country; MoGE: Ministry of General Education; MoH: Ministry of Health; PTA: Parent-Teacher Association; RCT: Randomized controlled trial; SRH: Sexual and reproductive health; STI: Sexually transmitted infection; ZCPH: Zambia Census of Population and Housing

\section{Acknowledgements}

The project is part of the portfolio of the Centre for Intervention Science in Maternal and Child Health (CISMAC), a Centre for Excellence (CoE) funded by the Research Council of Norway (RCN) and the UiB. We would like to thank Justus Hofmeyr (University of Fort Hare) for coming up with the idea for this study, and Halvor Sommerfelt (CISMAC), Leif Edvard Aarø (the Norwegian 
Institute of Public Health), Jose Martines (CISMAC), Ole Fritjof Norheim (University of Bergen), Simon Cousens (London School of Hygiene and Tropical Medicine), Kjell Arne Johansson (University of Bergen), and David Ross (WHO) for important inputs to the protocol. We are grateful to the MoGE, MoH, Forum for African Women Educationalists of Zambia (FAWEZA), Campaign for Female Education (Camfed), and Ministry of Community Development and Social Welfare for advice and to the DEBS offices in all the study districts for assistance in accessing schools that we would like to include in the study.

\section{Funding}

The Research Council of Norway will fund the trial through its Centres of Excellence scheme to the Centre for Intervention Science in Maternal and Child Health (CISMAC; project number 223269) and through the Global Health and Vaccination Programme (GLOBVAC; project number 248121). The University of Bergen (UiB) and the University of Zambia (UNZA) will fund the positions of the involved researchers from their institution, and the University of Bergen will fund fellowships for one PhD candidate and 2.5 postdoctoral fellows involved in the project. The Research Council of Norway and the University of Bergen have not played any role in study design or management. CISMAC has contributed with scientific support and advice.

\section{Availability of data and materials}

Not applicable.

\section{Authors' contributions}

IFS, PM, MM, JZ, EM, AB, MCM, OM, BT, CJ, LK, KF, KMM and RB have participated in the conceptualization and design of the trial. IFS, MM, PM, JZ, EM, MCM, CJ, LK, $A B, J S, K M M$ and $R B$ have participated in planning of the procedures and the detailed content of the interventions. IFS was responsible for development of the protocol, drafted, revised and finalized the manuscript, undertook the trial registration and conducted the sample size calculation. PM drafted the statistical analysis plan. OM, AB, BT, KF, LK, PM, JS, MCM, JZ, CJ, KMM and MM participated in the revision of the manuscript. All authors approved the final manuscript

\section{Competing interests}

The authors declare that they have no competing interests.

\section{Consent for publication}

\section{Not applicable.}

\section{Ethics approval and consent to participate}

The protocol has been approved by the University of Zambia Biomedical Research Ethics Committee (ref no 021- 06-15) and the Regional Ethics Committee of Western Norway (ref no 2015/895). Permissions have been obtained from the MoGE and MoH and district education offices in Zambia to conduct the trial in schools in the study districts and to engage teachers and $\mathrm{CHAs} / \mathrm{CHWs}$ in the community component. Since some girls and parents/ guardians may be sceptical to the intervention programme, but not to being interviewed, we will inform those who are reluctant to consent/assent that they can participate in the trial even if they do not want to receive the interventions. Girls who do not assent/consent, and the girls whose parents/guardians decline, will not be included in the study. There will be no disadvantages to those who do not participate, and participants can withdraw from the study at any point in time. All interviews will be conducted in privacy and strict confidentiality will be kept.

\section{Author details}

Center for Intervention Science in Maternal and Child Health (CISMAC) Centre for International Health $(\mathrm{ClH})$, University of Bergen, Bergen, Norway. ${ }^{2}$ Centre for International Health, University of Bergen, Bergen, Norway. ${ }^{3}$ Department of Global Public Health and Primary Care (IGS), University of Bergen, Bergen, Norway. ${ }^{4}$ Department of Public Health, School of Medicine, University of Zambia, Lusaka, Zambia. ${ }^{5}$ Department of Educational Psychology, School of Education, University of Zambia, Lusaka, Zambia. ${ }^{6}$ Christian Michelsens Institute, Bergen, Norway. ${ }^{7}$ Norwegian School of Economics, Bergen, Norway. ${ }^{8}$ Central Statistical Office, Zambia, Lusaka, Zambia.

Received: 15 July 2016 Accepted: 5 November 2016 Published online: 09 December 2016

\section{References}

1. United Nations Population Fund. Motherhood in childhood. Facing the challenge of adolescent pregnancy. The State of World Population 2013 New York: UNFPA; 2013.

2. Mokdad AH, Forouzanfar MH, Daoud F, Mokdad AA, El Bcheraoui C, MoradiLakeh $\mathrm{M}$, et al. Global burden of diseases, injuries, and risk factors for young people's health during 1990-2013: a systematic analysis for the Global Burden of Disease Study 2013. Lancet. 2016;387(10036):2383-401.

3. Gibbs CM, Wendt A, Peters S, Hogue CJ. The impact of early age at first childbirth on maternal and infant health. Paediatr Perinat Epidemiol. 2012;26:259-84.

4. Paranjothy S, Broughton H, Adappa R, Fone D. Teenage pregnancy: who suffers? Arch Dis Child. 2009;94(3):239-45.

5. Fall CHD, Sachdev HS, Osmond C, Restrepo-Mendez MC, Victora C, Martorell $\mathrm{R}$, et al. Association between maternal age at childbirth and child and adult outcomes in the offspring: a prospective study in five lowincome and middle-income countries (COHORTS collaboration). Lancet Glob Health. 2015:3(7):e366-77.

6. Ganchimeg T, Ota E, Morisaki N, Laopaiboon M, Lumbiganon P, Zhang J, et al. Pregnancy and childbirth outcomes among adolescent mothers: a World Health Organization multicountry study. BJOG. 2014;121 Suppl 1:40-8.

7. Ganchimeg T, Mori R, Ota E, Koyanagi A, Gilmour S, Shibuya K, et al. Maternal and perinatal outcomes among nulliparous adolescents in low- and middleincome countries: a multi-country study. BJOG. 2013;120(13):1622-30.

8. Althabe F, Moore JL, Gibbons L, Berrueta M, Goudar SS, Chomba E, et al. Adverse maternal and perinatal outcomes in adolescent pregnancies: the Global Network's Maternal Newborn Health Registry study. Reprod Health. 2015;12 Suppl 2:S8.

9. March of Dimes, PMNCH, Save the Children, WHO. Born too soon: the Global Action Report on preterm birth. Geneva: World Health Organization; 2012.

10. World Health Organization. WHO guidelines on preventing early pregnancy and poor reproductive health outcomes among adolescents in developing countries. Geneva: World Health Organization; 2011.

11. Central Statistical Office (CSO), Ministry of Health (MOH), Tropical Diseases Research Centre (TDRC), University of Zambia, Macro International Inc. Zambia Demographic and Health Survey 2007. Calverton, Maryland, USA: CSO, Macro International Inc; 2009.

12. Kenya National Bureau of Statistics (KNBS), ICF Macro. Kenya Demographic and Health Survey 2008-09. Calverton, MD: KNBS and ICF Macro; 2010.

13. National Statistical Office (NSO), ICF Macro. Malawi Demographic and Health Survey 2010. Zomba, Malawi, and Calverton, MD, USA: NSO and ICF Macro; 2011.

14. Alan Guttmacher Institute. Into a new world: young women's sexual and reproductive lives. New York: AGl; 1998.

15. Lloyd CB, Mensch BS, Mensch B. Marriage and childbirth as factors in dropping out from school: an analysis of DHS data from Sub-Saharan Africa. Popul Stud. 2008;62(1):1-13.

16. Schäferhoff $M$, Evans D, Burnett $N$, Komaromi $P$, Kraus J, Levin A, et al. Estimating the costs and benefits of education from a health perspective. Background paper for the Oslo Summit on Education for Development. Executive Summary. Oslo: Norwegian Agency for Development Cooperation - NORAD; 2015

17. Gakidou E, Cowling K, Lozano R, Murray CJ. Increased educational attainment and its effect on child mortality in 175 countries between 1970 and 2009: a systematic analysis. Lancet. 2010;376(9745):959-74. Epub 21 September 2010

18. Verspoor A, with the SEIA team. At the crossroads: choices for secondary education in Sub-Saharan Africa. Washington, DC: The International Bank for Reconstruction and Development/The World Bank; 2008.

19. Warrington M, Kiragu S. "It makes more sense to educate a boy": Girls 'against the odds' in Kajiado, Kenya. Int J Educ Dev. 2012;32(2):301-9.

20. Pengele M, Mazimba C. Promoting family planning in Zambia. Baseline study report. Scaling Up Family Planning Services in Zambia (SUFP) Program. London: Department for International Development; 2013.

21. Moore AM, Biddlecom AE, Zulu EM. Prevalence and meanings of exchange of money or gifts for sex in unmarried adolescent sexual relationships in sub-Saharan Africa. Afr J Reprod Health. 2007;11(3):44-61.

22. Taaffe J, Cheikh N, Wilson D. The use of cash transfers for HIV prevention are we there yet? Afr J AIDS Res. 2016;15(1):17-25.

23. Oringanje C, Meremikwu MM, Eko H, Esu E, Meremikwu A, Ehiri JE. Interventions for preventing unintended pregnancies among adolescents. Cochrane Database Syst Rev. 2016;2:CD005215.

24. Hindin MJ, Kalamar AM, Thompson TA, Upadhyay UD. Interventions to prevent unintended and repeat pregnancy among young people in low- 
and middle-income countries: a systematic review of the published and gray literature. J Adolesc Health. 2016;59(Suppl 3):S8-S15.

25. McQueston K, Silverman R, Glassman A. The efficacy of interventions to reduce adolescent childbearing in low- and middle-income countries: a systematic review. Stud Fam Plann. 2013;44(4):369-88.

26. Malhotra A, Warner A, McGonagle A, Lee-Rife S. Solutions to end child marriage. What the evidence shows. Washington, DC: International Center for Research on Women (ICRW); 2011.

27. Kalamar AM, Lee-Rife S, Hindin MJ. Interventions to prevent child marriage among young people in low- and middle-income countries: a systematic review of the published and gray literature. J Adolesc Health. 2016;59(Suppl 3):S16-21.

28. Duflo E, Dupas P, Kremer M, Sinei S. Education and HIV/AIDS prevention: evidence from a randomized evaluation in Western Kenya. Washington, DC: World Bank; 2006.

29. Hallfors D, Cho H, Rusakaniko S, Iritani B, Mapfumo J, Halpern C. Supporting adolescent orphan girls to stay in school as HIV risk prevention: evidence from a randomized controlled trial in Zimbabwe. Am J Public Health. 2011; 101(6):1082-8

30. Baird SJ, Garfein RS, Mclntosh CT, Ozler B. Effect of a cash transfer programme for schooling on prevalence of HIV and herpes simplex type 2 in Malawi: a cluster randomised trial. Lancet. 2012;379(9823):1320-9.

31. Baird S, Mclntosh C, Ozler B. Cash or condition? evidence from a randomized cash transfer program. Policy Research working paper series: 5259. Washington DC: World Bank; 2010.

32. Handa S, Peterman A, Huang C, Halpern C, Pettifor A, Thirumurthy H. Impact of the Kenya Cash Transfer for Orphans and Vulnerable Children on early pregnancy and marriage of adolescent girls. Soc Sci Med. 2015;141:36-45.

33. Alam A, Baez J, Del Carpio X. Does cash for school influence young women's behavior in the longer term? Evidence from Pakistan. Policy Research Working Paper 5669. The World Bank. 2011

34. Gulemetova-Swan M. Evaluating the impact of conditional cash transfer programs on adolescent decisions about marriage and fertility: the case of Oportunidades. University of Pennsylvania: ProQuest Dissertations Publishing; 2009.

35. Pettifor A, MacPhail C, Selin A, Gomez-Olive FX, Rosenberg M, Wagner RG, et al. HPTN 068: a randomized control trial of a conditional cash transfer to reduce HIV infection in young women in South Africa-study design and baseline results. AIDS Behav. 2016;20(9):1863-82.

36. Johnson BT, Scott-Sheldon LJ, Huedo-Medina TB, Carey MP. Interventions to reduce sexual risk for human immunodeficiency virus in adolescents: a metaanalysis of trials, 1985-2008. Arch Pediatr Adolesc Med. 2011;165(1):77-84.

37. Kirby DB, Laris BA, Rolleri LA. Sex and HIV education programs: their impact on sexual behaviors of young people throughout the world. J Adolesc Health. 2007;40(3):206-17.

38. Haberland NA. The case for addressing gender and power in sexuality and HIV education: a comprehensive review of evaluation studies. Int Perspect Sex Reprod Health. 2015:41(1):31-42.

39. Dupas P. Do teenagers respond to HIV risk information? Evidence from a field experiment in Kenya. Am Econ J:Appl Econ. 2011;3(1):1-34.

40. Duflo E, Dupas P, Kremer M. Education, HIV, and early fertility: experimental evidence from Kenya. Am Econ Rev. 2015;105(9):2757-97.

41. Underhill K, Operario D, Montgomery P. Abstinence-only programs for HIV infection prevention in high-income countries. Cochrane Database Syst Rev. 2007;17(4):CD005421.

42. Bandiera O, Buehren N, Burgess R, Goldstein M, Gulesci S, Rasul I, et al. Empowering adolescent girls: evidence from a randomized control trial in Uganda. 2012. Available at: http://econ.Ise.ac.uk/staff/rburgess/wp/ELA.pdf. Accessed 10 July 2016

43. Jewkes R, Nduna M, Levin J, Jama N, Dunkle K, Puren A, et al. Impact of stepping stones on incidence of HIV and HSV-2 and sexual behaviour in rural South Africa: cluster randomised controlled trial. BMJ. 2008;337:a506.

44. Taylor M, Jinabhai C, Dlamini S, Sathiparsad R, Eggers MS, De Vries H. Effects of a teenage pregnancy prevention program in KwaZulu-Natal, South Africa. Health Care Women Int. 2014;35(7-9):845-58.

45. Ross DA, Changalucha J, Obasi Al, Todd J, Plummer ML, Cleophas-Mazige B, et al. Biological and behavioural impact of an adolescent sexual health intervention in Tanzania: a community-randomized trial. AIDS. 2007;21(14):1943-55

46. Doyle AM, Ross DA, Maganja K, Baisley K, Masesa C, Andreasen A, et al. Long-term biological and behavioural impact of an adolescent sexual health intervention in Tanzania: follow-up survey of the community-based MEMA kwa Vijana Trial. PLoS Med. 2010;7(6):e1000287.
47. Plummer ML, Wight D, Obasi AIN, Wamoyi J, Mshana G, Todd J, et al. A process evaluation of a school-based adolescent sexual health intervention in rural Tanzania: the MEMA kwa Vijana programme. Health Educ Res. 2007; 22:500-12.

48. Wamoyi J, Mshana G, Doyle AM, Ross DA. Recall, relevance and application of an in-school sexual and reproductive health intervention 7-9 years later: perspectives of rural Tanzanian young people. Health Promot Int. 2013;28(3): 311-21.

49. Central Statistical Office (CSO) [Zambia], Ministry of Health ( $\mathrm{MOH})$ [Zambia], ICF International. Zambia Demographic and Health Survey 2013-14. Rockville, Maryland, USA: Central Statistical Office, Ministry of Health, and ICF International; 2014.

50. Banda R, Fylkesnes K, Sandøy IF. Rural-urban differentials in pregnancyrelated mortality in Zambia: estimates using data collected in a census. Popul Health Metrics. 2015:13:32.

51. Curriculum Development Centre. Comprehensive Sexuality Education Framework (Grades 5-12). Ministry of Education, Science, Vocational Training and Early Education. Lusaka: Curriculum Development Centre; 2014.

52. Beattie TS, Bhattacharjee $P$, Isac S, Davey C, Javalkar P, Nair S, et al. Supporting adolescent girls to stay in school, reduce child marriage and reduce entry into sex work as HIV risk prevention in north Karnataka, India: protocol for a cluster randomised controlled trial. BMC Public Health. 2015; 15(1):1-12.

53. Svanemyr J, Amin A, Robles OJ, Greene ME. Creating an enabling environment for adolescent sexual and reproductive health: a framework and promising approaches. J Adolesc Health. 2015;56 Suppl 1:S7-S14.

54. Patton GC, Sawyer SM, Santelli JS, Ross DA, Afifi R, Allen NB, et al. Our future: a Lancet commission on adolescent health and wellbeing. Lancet. 2016;387(10036):2423-78.

55. Fatusi AO. Young people's sexual and reproductive health interventions in developing countries: making the investments count. J Adolesc Health. 2016:59(Suppl 3):S1-3.

56. Smith MK. Paulo Freire and informal education: Infed.org; 2002. Available from: http://infed.org/mobi/paulo-freire-dialogue-praxis-and-education/. Accessed 30 Mar 2015

57. Malterud K. Systematic text condensation: a strategy for qualitative analysis. Scand J Public Health. 2012:40(8):795-805.

58. Udoh N. Guy Scott promises free education to Mpongwe voters. 2013. Available from: http://zambiareports.com/2013/02/01/guy-scott-promisesfree-education-to-mpongwe-voters/. Accessed 02 Aug 2015.

59. Hertrich $V$, Lesclingand M. Adolescent girls' migration and transition to adulthood in sub-Saharan Africa UNICEF. Office of Research-Innocenti. Available from: https://www.unicef-irc.org/article/1152/. Accessed 6 May 2016.

60. Brierley-Jones L, Crawley R, Lomax S. Stillbirth and stigma: the spoiling and repair of multiple social identities. Omega J Death Dying. 2014;70(2):143-68.

61. Chaaban J, Cunningham W. Measuring the economic gain of investing in girls. The girl effect dividend. Policy Research working paper series 5753. Washington, DC: World Bank; 2011

\section{Submit your next manuscript to BioMed Central and we will help you at every step:}

- We accept pre-submission inquiries

- Our selector tool helps you to find the most relevant journal

- We provide round the clock customer support

- Convenient online submission

- Thorough peer review

- Inclusion in PubMed and all major indexing services

- Maximum visibility for your research

Submit your manuscript at www.biomedcentral.com/submit 